\title{
SUJEITOS ENCORPADOS: AS TERAPIAS CORPORAIS E A EXPERIÊNCIA DA INTEGRAÇÃOCORPO-MENTE COMO FERRAMENTA TERAPÊUTICA
}

\author{
GABRIELA CUNHA DOS SANTOS
}

\begin{abstract}
RESUMO
Este trabalho baseia-se em etnografia realizada junto a terapeutas da Análise Bioenergética e busca contribuir no debate sobre as terapias corporais. Estas vertentes psicoterápicas vêm se expandindo nas últimas décadas, consolidando um mercado profissional (TAVARES, 2012), e passaram a ser absorvidas pela Política Nacional de Práticas Integrativas e Complementares (PNPIC) que oferece essas terapêuticas no SUS. Em um primeiro momento, apresento uma breve discussão acerca da relação entre as terapias corporais, o complexo alternativo e a Nova Era. Em seguida, a discussão segue reexaminando brevemente a dicotomia corpo-mente e a noção de subjetividade nos estudos da sociedade contemporânea, a partir do diálogo com a concepção de sujeito na bioenergética. Apoiando-se em entrevistas realizadas e outros registros etnográficos, realizo uma digressão acerca do processo de aprendizagem do oficio de terapeuta corporal.
\end{abstract}

PaLAVRAS-ChAVE

Terapias Corporais; Análise bioenergética; Corpo; Corpo-mente; Subjetividade.

\section{EMBODIED PEOPLE: BODY PSYCHOTHERAPIES AND THE EXPERIENCE OF MIND-BODYINTEGRATION}

\section{ASA THERAPEUTIC TOOL}

\begin{abstract}
This work is based on an ethnography made with therapists of a practice called Bioenergetic Analysis, and seeks to contribute to the discussion about corporal therapies, which have been expanding in the last decades consolidating a professional market (TAVARES, 2012) and being absorbed by the National Policy of Integrative and Complementary Practices (PNPIC). Since 2018, the bioenergetic analysis is offered in SUS, the Brazilian Health Care System. First, I present a brief discussion of the relationship between body therapies, the alternative complex and the New Age. Then, in the following, I examine briefly the body-mind dichotomy and the notion of subjectivity present in contemporary society studies in dialogue with the theoretical bases of the therapy. Finally, I discuss the learning process of therapists in bioenergetics.
\end{abstract}

\section{KEYWORDS}

Body therapies; Bioenergetic analysis; Body; Body-mind; Subjectivity.

\section{SUJETS COMPLETS: LES THÉRAPIES CORPORELLES ET L'EXPÉRIENCE DE INTÉGRATION CORPS-ESPRIT COMME OUTIL THÉRAPEUTIQUE}

\section{RÉSUMÉ}

Ce travail est basé sur une ethnographie réalisée avec des thérapeutes de l'analyse dite bioénergétique et cherche à contribuer au débat sur les thérapies corporelles développé au cours des dernières décennies. Ces thérapies ont consolidé un marché professionnel (TAVARES, 2012) et ont été absorbées par le programme nationale PNPIC (Politique Nationale des Pratiques Intégratives et Complémentaires), qui propose des traitements thérapeutiques dans le SUS (Système Unique de Santé, sécurité sociale brésilienne). D'abord, nous présentons une brève discussion sur la relation entre les thérapies corporelles, le complexe alternatif et le 
nouvel âge. De suite, nous examinons la dichotomie esprit-corps et la notion de subjectivité dans la société contemporaine à partir de l'analyse ethnographique de la thérapie. Enfin, nous nous éloignons brièvement du processus d'apprentissage de la profession de thérapeute en bioénergétique.

\title{
MOTS-CLÉS
}

Thérapies corporelles; Analyse bioénergétique; Le corps; Corps-esprit; La subjectivité.

\section{SUJETOS CON CUERPO: TERAPIAS CORPORALES Y LA EXPERIENCIA DE INTEGRACIÓN CUERPO-MENTE COMO HERRAMIENTA TERAPÉUTICA}

\begin{abstract}
RESUMEN
Este trabajo se basa en etnografía hecha junto a terapeutas de la terapía llamada análisis bioenergética y busca contribuir en el debate sobre las terapias corporales, práticas que vienen expandiéndose en las últimas décadas, consolidando un mercado profesional (TAVARES, 2012) y siendo absorbidas por la Política Nacional de Prácticas Integrativas y Complementarias (PNPIC). Recientemente, la análisis bioenergética fue incluida como parte de la oferta en el SUS, el sistema de salud brasileño. En un primer momento, se presenta una breve discusión sobre la relación entre las terapias corporales, el complejo alternativo y la Nueva Era para luego reexaminar la dicotomía cuerpo-mente y la noción de subjetividad en la sociedad contemporánea, basándose en un análisis etnográfico de la terapia. Por fin, se hace una breve digresión sobre el proceso de aprendizaje del oficio de terapeuta en bioenergética.
\end{abstract}

\section{PALABRAS CLAVE}

Terapias corporales; Análisis Bioenergética; Cuerpo; Cuerpo-mente; Subjetividad. 


\section{INTRODUÇÃO - DA PSICANÁLISE À NOVA ERA: A DIFUSÃO DAS TERAPIAS CORPORAIS E A BIOENERGÉTICA NO CONTEXTO BRASILEIRO}

Nas ciências sociais, as terapias corporais são compreendidas como ramificação de dois fenômenos distintos: a difusão do campo psicológico nos centros urbanos e o complexo alternativo (RUSSO, 1993). A difusão do campo psicológico, que é também designado como "cultura psicológica" ou simplesmente "cultura psi", alicerça-se em uma noção específica de individualidade que é pautada pelo crescimento do segmento em meados do século XX no Ocidente.

Do ponto de vista genealógico, as terapias corporais são consideradas póspsicanalíticas. A psicanálise está prestes a completar um século de sua inserção no contexto brasileiro: a fundação da Sociedade Brasileira de Psicanálise ocorreu em 1927 e foi sucedida pela chegada da International Psychoanalytical Association (IPA) nos anos 1940 (RUSSO, 2002). Inicialmente, foi frequentada por camadas de elite, sobretudo de artistas renomados do modernismo brasileiro e da aristocracia cafeeira paulistana (SAGAWA, 1985 apud RUSSO, 1993).

Já na segunda metade do século XX, o campo foi transformado pela elaboração de um "nicho de mercado" - criando trabalhadores e também consumidores (CASTEL, 1987) - e, como consequência, passando a ser também composto por estratos médios das sociedades que experimentavam a difusão psicológica em seus meandros. Além disso, foi inserida nos meios de comunicação de massa e também nas universidades. As terapias corporais seguem esse fluxo e passam a compor atividades extracurriculares das universidades a partir do final da década de 1970 no Brasil (RUSSO, 1993).

Nos estudos sobre esse segmento nas ciências sociais, o complexo alternativo aparece como a via de análise mais frequentemente acionada. Ele é compreendido como um composto técnico-prático referente à diversidade de crenças (idem, 1993) que teria surgido e se instaurado na sociedade como resultado da difusão do que é denominado Nova Era: uma herança dos movimentos de contracultura que mobilizaram camadas médias e altas em grandes centros urbanos ocidentais nos anos 1960 e 70 (OLIVEIRA, 2012; SANTOS, 2013; BERLINCK, 1989; 1991; MALUF, 2005; CAROZZI, 1999).

A contracultura foi associada às expressões de contestação aos paradigmas do status quo daquele momento. Direitos humanos, feminismo, igualdade racial e outras pautas de estratos sociais não-hegemônicos passaram a compor a agenda política através de mobilizações diversas na sociedade civil, que por vezes privilegiavam intervenções artísticas que pautavam o princípio da autonomia como via de ação. No Brasil, os movimentos sociais 
contestavam a instauração da ditadura militar e sua repressão. Como cantava o então tropicalista Caetano Veloso em uma canção gravada na época, "é proibido proibir"1.

Рara além da agenda política, grupos começaram a se unir em busca de ideais de mudança pessoal, centralizando o indivíduo na dinâmica social (RUSSO, 1993; SANTOS, 2013) - o que posteriormente forneceria insumos para o diálogo com o campo psicológico que seguia em expansão.

Desde meados dos anos 1930 do século XX, havia forte contato com a cultura norteamericana e isto permitiu a absorção de elementos culturais estadunidenses pelas metrópoles brasileiras: desde o American Way of Life ao movimento hippie. As artes brasileiras criaram sincretismos variados a partir de influências locais e estrangeiras (GUIMARÃES, 2012). Assim como acontecia nos EUA, viu-se crescer nas metrópoles brasileiras o número de "buscadores" (SANTOS, 2013), pessoas que almejavam um outro modo de vida, pautado por ideais de libertação e muitas vezes relacionado ao universo naturalista². O ambiente de contestação da contracultura foi, portanto, fomentador do desejo pela autonomia e de práticas que visavam promover essa experiência aos sujeitos que Ihes foram adeptos.

"É verdade que os rebeldes culturais eram pacifistas pelo sentimento e pela simpatia aos direitos civis. Além disso, eles achavam que poderiam mudar o mundo - mas não se organizaram para isso. Provavelmente eles pensaram que poderiam mudar o mundo porque eles estavam mudando a si mesmos, o que seria a mesma razão solipsista pela qual eles não fizeram disso um projeto político" (SAHLINS, 2009, p. 5, tradução (ivre).

O ideário de mudança pessoal compunha a expressão da contracultura e da Nova Era. Concomitantemente, a cultura psicológica se adensava e complexificava (RUSSO, 1993). É importante ressaltar aqui que a Análise Bioenergética foi criada e sistematizada nos Estados Unidos a partir de revisão dos trabalhos de Wilhelm Reich por Alexander Lowen e John Pierrakos ${ }^{3}$ nos anos 1950, e sua chegada oficial ao Brasil data dos anos 1980 (SANTOS, 2018). O foco no corpo enunciado por tais terapêuticas é apontado como referente a um segundo momento de expansão das práticas alternativas neste mesmo período (MALUF, 2005).

\footnotetext{
${ }^{1}$ A Tropicália, assim como a Jovem Guarda, surgem como expressões da contracultura no Brasil. Enquanto a segunda é entendida como uma certa imitação da contracultura estadunidense, a primeira se apresenta como um resultado de um processo dialético intercultural (GUIMARÃES, 2012).

${ }^{2}$ Ver Coiote, romance de Roberto Freire, escrito na década de 1980. O livro fornece uma boa ilustração do contexto descrito: um romance redigido por um terapeuta corporal dissidente da psicanálise a nas paisagens de São Thomé das Letras, SP, onde até hoje encontram-se comunidades alternativas no Brasil.

${ }^{3}$ Pierrakos e Lowen rompem para o primeiro dar início aos trabalhos com a vertente Core Energetics, que possui os mesmos pressupostos teóricos, mas trabalha com elementos da filosofia Pathwork.
} 
Por sua vez, a predominância da relação entre as terapias corporais e o movimento da Nova Era mobiliza abordagens pelo recorte de religião e espiritualidade. Neste viés, prevalece a análise do fenômeno do pluralismo terapêutico com base na diversidade espiritual (TAVARES, 2010; MALUF, 2013). Do ponto de vista teórico, o debate acerca do complexo alternativo é pautado através das possíveis relações de seus fundamentos com os das ciências biomédicas e sua hegemonia dada pela modernidade científica. Destarte, ele pauta, ao menos em certa medida, a noção de holismo na compreensão do sujeito (RUSSO, 1993).

\begin{abstract}
"No que diz respeito às terapias corporais, definindo brevemente, isso se daria através da concepção que estas possuem de que os processos de socialização e repressão do sujeito constituem marcas psíquicas que reverberam corporalmente. Isto posto, as técnicas de cuidado são destinadas ao corpo e à expressividade para que a transformação aconteça. O resultado de sua eficácia é o bem-estar em que vive um sujeito integrado. Por sua vez, isso seria dado pela reconexão entre os domínios do corpo e da mente, que seriam apresentados de maneira fragmentada pela sociedade moderna, e a visão biomédica (BONET, 2004; FOUCAULT, 1977). É importante ressaltar que as práticas que se relacionam comumente como referentes à Nova Era não foram necessariamente produzidas durante o período, mas sim, e de certa forma, resgatadas e difundidas pelos "buscadores" como ferramentas para atingir seus objetivos pessoais" (SANTOS, 2018, p. 24).
\end{abstract}

Do ponto de vista psicológico, as psicoterapias corporais surgem como dissidentes da psicanálise freud-lacaniana e sua ênfase na "palavra", priorizando o legado reichiano, a ênfase no "corpo" e uma subjetividade pautada na relação corpo-psiquismo (NASCIMENTO, 2012). Nessa lógica a saúde engloba, então, "os aspectos físicos, psíquicos, emocionais e sociais" (BRASIL, 2018, p. 14).

Pela perspectiva das ciências sociais, elas são compreendidas como vertentes póspsicanalíticas e exemplos de fenômenos que marcam uma nova subjetividade embasada no individualismo referente ao campo psicológico (CASTEL, 1987) e, ao mesmo tempo, uma resposta aos movimentos de contracultura, conforme dito anteriormente (RUSSO, 1993; 1991; SANTOS, 2018). Ilustram também exemplos do que seria um sujeito híbrido na lógica latouriana, através do tensionamento da dicotomia corpo-mente, que se relaciona ao ideário da Nova Era pela associação da natureza ao corpo e da mente à cultura (ALBUQUERQUE, 2001). Ou ainda, assinalam através do foco no corpo um possível "desdobramento e a expressão de uma cultura mais ampla da subjetividade no contemporâneo" (MALUF, 2005, p. 159).

De acordo com o livro Conhecendo as Práticas Integrativas e Complementares em Saúde: Bioenergética do Ministério da Saúde:

"A bioenergética, também conhecida como análise bioenergética (AB), se originou do campo das psicoterapias corporais e se insere, neste contexto, como uma técnica terapêutica relevante por estar alinhada fortemente ao paradigma de saúde integrativa. De acordo com Barreto (2011), a bioenergética usa uma visão vitalista do ser humano e do mundo, lança um olhar integral para a saúde do sujeito, faz uso de recursos terapêuticos não invasivos, baseados no vínculo humano seguro, em toques 
terapêuticos cuidadosos e exercícios corporais e respiratórios que procuram potencializar a vitalidade das pessoas" (BRASIL, 2018, p. 9-10).

O presente artigo resulta de reflexões elencadas a partir da minha pesquisa de mestrado com a análise bioenergética. Realizei trabalho de campo junto a terapeutas do ramo entre os anos de 2016 e 2018 nas cidades de Brasília/DF e São Paulo/SP, acompanhando atividades de aprendizagem e formação, e também eventos acadêmicos e institucionais do segmento.

A terapêutica vem seguindo um movimento de institucionalização na saúde pública brasileira, passando a compor a Política Nacional de Práticas Integrativas e Complementares (PNPIC) em 2018. É predominantemente oferecida no contexto da saúde privada, sendo a presença na saúde pública pontual, através de projetos promovidos pelas entidades mobilizadas pela sua difusão na esfera estatal. Tais projetos tomaram lugar em Centros de Atenção Psicossocial (CAPS), escolas e universidades públicas no país.

Algumas escolas de formação possuem uma clínica social, uma maneira de oferecer o serviço à comunidade visando sua acessibilidade sócio-econômica e que segue o modelo de clínicas de atendimento à população e de cursos de saúde em universidades públicas e privadas. A clínica social é uma iniciativa também presente na atuação de outras terapias do complexo alternativo como, por exemplo: medicina chinesa, body talk, core energetics e acupuntura.

No Brasil encontra-se a sede da Federação Latino-americana de Análise Bioenergética, que conta com seis sociedades filiadas: uma argentina e cinco brasileiras (entre as regiões nordeste, centro-oeste e sudeste). É importante considerar a atuação de profissionais não filiados, o que levanta questões sobre o quantitativo no cenário brasileiro.

Durante a pesquisa, por diversas vezes escutei que suas práticas não teriam relação com a espiritualidade no sentido de "religiosidade e transcendência", como indicaria grande parte do aparato bibliográfico sobre o tema, mas seriam compreendidas como uma vertente psicoterápica dentre as possíveis. Nesse sentido, a Nova Era não parecia ser suficiente para constituir-se como a priori analítico, por mais que haja proximidade ontológica entre ela e as práticas alternativas (TONIOL, 2017). Dessa forma, argumentei em minha dissertação de mestrado o que já vinha sendo sugerido por alguns especialistas do tema: a Nova Era surge como categoria êmica das próprias ciências sociais - referente aos alicerces teóricos da disciplina e à sua maneira de organizar e categorizar os fenômenos das nossas sociedades (D'ANDREA, 2000). Ainda assim, corroboro ali com a tese de que a contracultura tenha fornecido o terreno ideológico para sua difusão (SANTOS, 2018; RUSSO, 1991; 1993).

"A variedade dos fenômenos descritos como característicos da Nova Era, contudo, aliada à insistente tendência dos cientistas sociais da religião em imputar a categoria em suas etnografias, permite desconfiar de que estejamos diante de uma situação em que o emprego sistemático de certa linguagem analítica tenha aprisionado a multiplicidade das realidades observadas na ficção criada para descrevê-las" (TONIOL, 
2015, p. 20).

Anteriormente, sinalizei que o presente momento da terapêutica apresenta uma forte herança do legado psicanalítico institucionalizado (SANTOS, 2018). A formação curricular para obtenção de título é complexa e burocrática. Atualmente, profissionais e entidades da bioenergética seguem em movimento de busca pela consolidação no campo da pesquisa - tanto como eixo quanto como objeto -, mobilizado pelo objetivo de legitimação perante instâncias formais e sua inserção e difusão na saúde pública de maneira mais ampla.

Nos últimos anos institutos e seus representantes, de diversas regiões do país, vêm se mobilizando em conselhos federais e regionais com o intuito de promover a terapêutica para além da PNPIC. O campo profissional visa estabelecer diálogos, não negando a hegemonia biomédica, ainda que sua base epistêmica de junção corpo-psiquismo ofereça um novo paradigma à modernidade científica ${ }^{4}$. Dessa forma, o "pluralismo terapêutico" vem se mostrando, portanto, como fenômeno complexo que elenca questões que ultrapassam as fronteiras dos estudos de religião.

A seguir, trarei elementos para um debate teórico acerca da relação entre corpo e subjetividade estabelecida pela terapêutica.

\section{A DISJUNÇÃO CORPO-MENTE NA CONSTRUÇÃO DA SUBJETIVIDADE PARA A BIOENERGÉTICA ${ }^{5}$}

O paradigma do corpo vem sendo revisitado desde os trabalhos pioneiros de Hertz (1909), Mauss (1934) e Leenhardt (1947), em constante diálogo com o modelo naturezacultura representado também pelas dicotomias corpo-mente e social-biológico e outras formas correlatas6. Por vezes, a corporalidade surge como campo de tensão e encontro de tais dimensões nos estudos do corpo.

Com o amadurecimento do campo na segunda metade do século XX, o corpo passa a ser entendido do ponto de vista relacional, o que permite a compreensão do discurso médico-biológico como um paradigma passível de ser revisitado (MALUF, 2002). Por conseguinte, abre-se espaço para o legado da fenomenologia e sua ênfase no aspecto processual e perceptivo da corporeidade.

"A possibilidade decorrente das mudanças culturais e históricas delineadas no início

\footnotetext{
${ }^{4} \mathrm{O}$ Instituto Internacional de Análise Bioenergética fomenta pesquisas através do concurso IIBA Awards, que premia os trabalhos em diversas categorias. O encontro internacional é anual e encontra-se na sua $25^{\text {a }}$ edição.
}

\section{${ }^{5}$ Ao longo do presente texto todas as categorias êmicas serão grafadas em itálico, bem como expressões e trechos retirados de entrevistas.}

${ }^{6}$ Ver Lock, 1993. 
desta introdução, de que o corpo possa ser entendido como um lugar de subjetividade, é uma fonte de desafio às teorias da cultura nas quais mente/sujeito/cultura são implantadas em paralelo com e em contraste com o corpo/objeto/biologia. Grande parte de nossa teorização é herdeira do legado cartesiano na medida em que privilegia o conjunto mente/sujeito/cultura na forma de representação, seja em termos de regras e princípios da antropologia social, seja de signos e símbolos pela antropologia semiótica/simbólica, texto e discurso por antropologia estrutural/pós-estrutural, ou conhecimento e modelos por antropologia cognitiva" (CSORDAS, 1994, p. 9, tradução livre).

Conforme amadurecia a discussão, a corporalidade passou a ser abordada em correspondência com a noção de pessoa, com ênfase no aspecto processual e prático deste fenômeno ${ }^{7}$. O esforço de avançar no debate sobre corpo e subjetividade é trazido também no trabalho de Le Breton, que considera a noção de corpo como sendo inseparável da subjetividade. Nessa via, pensá-lo como uma realidade objetiva tal como o faz a racionalidade moderna seria alcançar uma compreensão limitada do ponto de vista epistemológico (LE BRETON, 2011). Uma preocupação similar aparece no trabalho de Csordas através da noção de embodiment, que busca entender a experiência cultural como corporificada (CSORDAS, 1994).

\footnotetext{
"A questão do corpo requer mais do que conciliar teoria com prática. Traz consigo a dificuldade de as pessoas terem e serem corpos (236: 1); a subjetividade e sua relação com a biologia e a sociedade não podem ser ignoradas" (LOCK, 1993, p. 136, tradução livre).
}

Nesse sentido, apresento a seguir como a subjetividade na bioenergética demonstra se alinhar teoricamente com a crítica. Na sua concepção de saúde há um simultâneo equilíbrio mental, emocional e fisiológico baseado no princípio de unidade do organismo humano (LOWEN, 1988). Ou seja, não se propõe a recusa das categorias utilizadas pela racionalidade científica e o debate acadêmico produzido até meados do século XX - quando a terapêutica foi sistematizada-, mas, sim, o entendimento destas dimensões como interrelacionadas na dimensão da saúde.

A Análise Bioenergética reivindica uma subjetividade pautada pela experiência de integração, ou seja, na compreensão da pessoa através da unidade corpo-psiquismo (NASCIMENTO, 2012). Nessa ótica, o corpo, para os terapeutas corporais, não é destacável do sujeito, mas sim parte de sua constituição e expressão de sua subjetividade. Devido ao caráter de continuidade corpo-mente, a via psicoterápica somática seria uma ferramenta capaz de fazer "enxergar a pessoa" (HELFAER, 2015 apud BRASIL, 2018, p. 11), e infortúnios fisiológicos podem ser compreendidos em conformidade com as dimensões mentais e afetivas.

\footnotetext{
${ }^{7}$ Ver Seeger, Da Matta e Viveiros De Castro, 1979 e Viveiros De Castro, 1996.
} 
Vejamos a seguinte narrativa. Quando estimulado a falar sobre sua experiência com a bioenergética, Lúcio ${ }^{8}$, um psicólogo que à época da entrevista encontrava-se em vias de conclusão de sua formação de cinco anos na terapêutica, elucida a concepção que possui acerca de si mesmo:

\begin{abstract}
(...) porque a gente tem mania de objetificar tudo, então a gente fala do corpo, a gente fala da mente e, se eu tenho uma mente, se eu tenho um corpo, onde é que está o eu no meio disso? Então quando a gente está falando do corpo não é do meu corpo, é de mim, eu sou o meu corpo, tanto quanto eu sou a minha vida psíquica.
\end{abstract}

Na sua visão, a vida moderna apresenta-se como um campo de produção de desequilíbrios ao protagonizar a mente e seus processos em detrimento da dimensão afetiva que, por sua vez, também é compartimentada do universo fisiológico. Ele entende que o contexto social leva as pessoas a uma condição de dissociação que seria marcada pelo ato de se ignorar o que a gente sente e distinguir do que a gente pensa. Isso acarreta na evitação da percepção e expressão das emoções e por conseguinte da resolução dos conflitos emocionais e queixas existenciais que podem acometer o sujeito - dado na totalidade das dimensões supracitadas. Com o tempo, a depender da intensidade e da frequência destes infortúnios, acontece sua somatização em dores, doenças e quadros de sofrimento. Рara a bioenergética, o adoecimento deve ser abordado de maneira integrativa, ou seja, levando em consideração este princípio de unidade.

Além disso, há o caráter processual na visão de sujeito produzida pela terapêutica, expressa na seguinte fala de Lúcio: Nesse sentido, assim como eu falei de saúde há pouco, eu acho que é uma trajetória dinâmica e um objetivo que talvez seja alcançado em alguns momentos, mas que nunca vai ser alcançado de maneira plena e definitiva. Assim sendo, o sujeito da bioenergética pode ser entendido como um devir. Podemos, portanto, analisar essa percepção pela noção de ontogênese de Simondon (1992). Nesta abordagem:

"A imagem tradicional da teoria do conhecimento na qual a psicologia manteve-se apoiada e que separa e opõe sujeito e objeto (percepção e mundo dados ontologicamente), deve ser sobreposta por uma perspectiva em devir (ontogênese) que pensa a "percepção" e o "mundo" como "coemergentes", como duas dimensões da experiência que se distinguem, porém sem se separar" (MELO, 2017, p. 105).

Lúcio apresenta o estado de integração como algo não-definitivo, ainda que sua experiência se torne cada vez mais acessível conforme o processo terapêutico evolui. Além disso, a experiência de dissociação é uma condição intrínseca à vida moderna e importante para sua manutenção. Dessa forma, a expressividade acrítica das emoções é rechaçada pela abordagem, que visa promover saúde através da relação entre o individual e coletivo, sem que uma esfera seja privilegiada em detrimento da outra.

\footnotetext{
${ }^{8}$ Os nomes dos entrevistados para a pesquisa foram trocados a fim de garantir seus anonimatos.
} 
O estado de reconexão ou integração é também definido como grounding, uma menção ao fluxo de energia que promove a sensação de aterramento aos sujeitos a partir do encontro com a sua própria essência e a retomada da vitalidade (OLIVEIRA; LIMA, 2015). O grounding é uma experiência que tem relação com a postura corporal, a posição dos pés em relação ao contato com o chão e a sensação de contato com a realidade, que é dada pela capacidade do sujeito de identificar suas percepções e sensações em relação aos fatores externos e agir de maneira benéfica. Trata-se de uma definição figurativa do movimento da energia na experiência de integração corpo-mente. Quando neste estado, o sujeito estaria orientado para a experiência do prazer, que aumenta a "autoconfiança" e o "senso de segurança" (LOWEN, 1988), qualidades entendidas como sinais de saúde pelo campo psicológico. Estar em grounding seria:

(...) estar de posse da realidade da sua vida. Que pode ser, metaforicamente falando, que você está sob seus pés, plantado no chão. Mas acho que é o objetivo de qualquer terapia. Pés no chão e posse da realidade da sua vida. (Marcela, em entrevista)

O trabalho da bioenergética e seu viés psicossomático centraliza a experiência subjetiva na dimensão da saúde, tornando o sujeito capaz de adotar práticas de manutenção da saúde pelo princípio da autorregulação, como a terapêutica define o processo de mediação exercido pela pessoa no mundo. Dessa maneira, a bioenergética debruça-se sobre questões existenciais do sujeito, tal como a psicanálise e outras abordagens verbais, possuindo uma diferença metodológica fundamental: em vez da análise de narrativas verbais, utiliza-se do "toque terapêutico, prática de exercícios corporais e outros recursos não invasivos" para o "processo de desenvolvimento, autoconhecimento e tratamento do indivíduo de modo integral" (BRASIL, 2018, p. 13).

Lidar com um "corpo dividido" faz parte do cotidiano destes profissionais não somente pela leitura que fazem da experiência do sujeito na sociedade contemporânea. Há, também, interfaces de trabalho quando compõem equipe junto a médicos. No trabalho de Roberta, por exemplo, isso se faz uma constante. Ela realiza seus atendimentos a pessoas que são encaminhadas por médicos, e precisa adequar seus relatórios às diretrizes do Código Internacional de Doenças: o CID-10.

Neste caso em específico, trabalha como uma tradutora, realizando a comunicação entre o entendimento da bioenergética e suas categorias com as utilizadas pela medicina. Mesmo compreendendo que o sujeito e seu organismo são fluxos contínuos entre corpo e mente, o objetivo da terapêutica não é a de substituir a biomedicina, mas, em alusão ao resultado do trabalho terapêutico, fornecer elementos para flexibilizar sua rigidez.

Nesse sentido, o sistema de conhecimento proposto pela terapêutica aparece como ferramenta para reflexão acerca da própria noção de "saúde mental" como eixo ramificado de "saúde" referente às questões psíquicas, afetivas e emocionais do sujeito, uma 
vez que para esta vertente o sofrimento psíquico é entendido em conjunção com o corpo como território afetivo e subjetivo. Isto também pode ser apreendido pelo enunciado de Latour (2008) que relaciona o corpo ao movimento de afetar e ser afetado pelo mundo e pelo princípio ontogenético de Simondon (2002), abordagens filosóficas que possibilitam diálogo com os questionamentos de Le Breton (2011) e Lock (1993). Sendo assim, o trabalho corporal é ponto de partida para a "revolução do self" (RUSSO, 1993).

\section{O TRABALHO CORPORAL}

Conforme enunciado no item anterior, corpo e pessoa se apresentam em continuidade na perspectiva da Análise Bioenergética. Para a terapêutica, a subjetivação é um processo que marca a dimensão da experiência como definidora de padrões orgânicos. Contemplando o componente psicanalítico, compreende a gradual construção da subjetividade através do cuidado e das relações que são tecidas nos primeiros anos de vida da pessoa (MENDONÇA, 2012; ANTONIO, 2015). Essas relações moldam o sujeito em sua integralidade.

Destarte, o sujeito da bioenergética é composto pelas implicações somáticas de sua vivência psíquica. Tais implicações definem a distribuição da energia no organismo e dão origem ao que é chamado estrutura, que é manifestada em características físicas e fisiológicas que formam certos padrões corporais. Estes, por sua vez, foram e vêm sendo catalogados e sistematizados desde os trabalhos iniciais de Alexander Lowen $(1977$; 1985). A personalidade, geralmente atribuída como domínio da mente, é "entendida nos termos do corpo e de seus processos energéticos que estão relacionados ao seu estado de vitalidade", possuindo, conforme dito anteriormente, uma identidade funcional entre o caráter psíquico e a estrutura corporal. Dessa maneira, possibilita que a energia seja distribuída no organismo através da interação dinâmica entre corpo e afetos (pensamentos, sentimentos, atitudes e emoções), sendo a respiração uma chave para seu equilíbrio no organismo. (BRASIL, 2018, p. 12-14).

A estrutura de caráter fornece pistas para o comportamento humano e este pode, então, ser trabalhado a fim de se atingir a sensação de bem-estar para aqueles que se submetem à terapia. Assim como outras terapêuticas do campo da saúde mental, o objetivo é o de diminuir a intensidade da experiência de sofrimento e dor das pessoas em relação às suas próprias queixas.

Neste caso, o viés da representação é substituído pela noção material. A composição corporal não representa a tristeza, a raiva ou alguma outra defesa, mas sim marca os lugares nos quais as emoções estão energeticamente acumuladas. São registros, 
construções sociais e históricas que as experiências do passado imprimiram nos sujeitos, sendo o corpo, portanto, constituído por elas.

Podemos dizer que, para eles, o corpo conta a própria história, expressa em sua composição corporal e nos seus padrões de comportamento. Assim sendo, o corpo seria, portanto, a própria materialização das experiências de vida e a vida em si mesma. É através do sistema corpo-mente que o terapeuta encontra seu caminho de ação, informado a ele por um campo de elementos que vão desde uma entonação, um olhar, até a constituição fisiológica. Compreendendo essa história, conduz sua intervenção orientada a movimentar a energia e trazê-la de volta ao fluxo saudável do estado de grounding.

Além dos atendimentos em terapia individual, uma variação do setting ${ }^{9}$ psicoterápico convencional são os atendimentos em grupo. A análise bioenergética trabalha também no formato de grupos de movimento, que podem ser denominados de classes de exercícios e consistem na prescrição de certos exercícios corporais com base em um tema escolhido pelo(s) próprio(s) terapeuta(s) que ministra os grupos. Estes podem ser definidos como o intermédio entre terapia e ginástica. Os grupos trabalham temas gerais como medo da vida, raiva e respiração e incentivam a expressão das emoções.

Em maior ou menor profundidade, o intuito do trabalho terapêutico é de operar no registro da pessoa e flexibilizar sua estrutura corporal através das técnicas utilizadas. A mudança do registro seria o processo de transformação da maneira como a pessoa experimenta a vida à sua volta, incluindo suas atitudes e percepções acerca do mundo.

Todavia, é importante ressaltar que o fenômeno de transformação pessoal não se refere somente à bioenergética, mas sim ao campo psicológico como um todo (CASTEL, 1987; RUSSO, 1993). O que se altera no caso em questão é o protagonismo da corporeidade como campo majoritário da intervenção psicoterápica, que pauta uma concepção de subjetividade encorpada à cultura "psi".

\section{APRENDENDO A VIVER NO CORPO}

Seguindo o legado psicanalítico, o aprendizado do ofício de terapeuta em bioenergética é estruturado pela herança de Escola (ANTONIO, 2015) que tem como base a necessidade da experiência subjetiva daquele que almeja tornar-se analista. Para exercer a profissão, há obrigatoriedade de submissão dos próprios alunos dos cursos de formação a sessões de terapia iniciadas concomitantemente ao curso prático-teórico, que dura em torno

\footnotetext{
${ }^{9}$ Setting é como se chama o tipo de relação que é construída no espaço do consultório entre terapeuta e cliente (SANTOS, 2018, p. 123).
} 
de cinco anos para ser finalizado e possui duas provas práticas como exigência para obtenção de certificado.

Os avaliadores, por sua vez, são detentores de títulos reconhecidos pelo Instituto Internacional de Análise Bioenergética - IIBA - que os autoriza a formar novos terapeutas. Conforme adquire experiência, o terapeuta em formação passa a atender clientes externos em uma estrutura chamada de atendimento supervisionado.

A submissão à terapia provoca a experiência da própria vida sob a ótica de transformação pessoal. Dessa forma, ao experimentarem um estado que fundamenta a autoexpressão de maneira plena, os terapeutas passam a ser capazes de possibilitar essa experiência a outros. Assim, paulatinamente vão incorporando as habilidades necessárias ao ofício.

Em The perception of environment (2000) Tim Ingold atribui o conceito de skill ao desenvolvimento de habilidades adquiridas no engajamento no mundo. Ele apresenta o conceito como composto por cinco dimensões: intencionalidade e funcionalidade da prática; atribuição a um sistema de relações da prática; cuidado, julgamento e destreza; aprendizagem pela prática; produção de um trabalho direcionado à geração de um novo produto. Por diversas vezes ao longo de sua trajetória, Ingold $(2011 ;$ 2013; 2015; 2018) revisita o tema e, ao aprofundar-se, afirma que "skill é o terreno através do qual o conhecimento surge" (INGOLD, 2018, p. 159, tradução livre). Nesse viés, as habilidades construídas sob à luz do conceito de skill referem-se ao engajamento que envolve a dimensão da prática para sua constituição, sendo essa intrínseca aos domínios da percepção e ação e pouco relacionada com a ideia de controle, privilegiando uma noção associativa. Através das habilidades adquiridas no processo de submissão à terapia, associadas com a aprendizagem teórica da bioenergética, os terapeutas desenvolvem sua maneira de trabalhar:

Porque acontece muito, no sentido de que eu proponho um exercício não com um propósito fechado, mas como uma possibilidade, então eu não sei o que vai acontecer naquele momento propondo aquele exercício, mas existe algum sentido para ter proposto aquilo. (Lúcio, em entrevista)

Assim, a relação de causa e efeito é transposta pela percepção subjetiva estabelecida no setting terapêutico. O sentido seria o indicativo de uma questão ou elemento que não foi verbalizado até aquele momento, mas é perceptível devido à habilidade adquirida.

Desse modo, não se trata da execução de um roteiro pré-definido por uma cartilha que prescreve a certas estruturas exercícios específicos, ainda que haja orientações específicas no aparato teórico que fundamenta a disciplina, mas um ofício construindo através da imprevisibilidade que a subjetividade carrega consigo. 
Tive a oportunidade de participar de algumas classes de exercícios. Por vezes, os exercícios me conduziram a sensações de mal-estar, e também de bem-estar. Retomando a definição anteriormente apresentada, as classes de exercícios são momentos de terapia em grupo nos quais questões específicas (por exemplo: raiva, medo, alegria, limitações) são trabalhadas sem que se intensifique o processo terapêutico.

Em um destes momentos, realizava um movimento denominado bend-over, que consiste em, estando em pé, curvar-se para frente com os joelhos levemente flexionados e paralelos. Durante o exercício, realizava os passos dados pelas instrutoras da classe mas mantinha meus olhos fechados, por entender que seria um momento de relaxamento. Em seguida, percebi um mal-estar marcado por lábios secos, formigamento e frio nos pés. Enquanto tentava compreender aquilo que acontecia comigo, afinal estava ali com intenções de pesquisa, as duas terapeutas que conduziam a classe composta por cerca de cinco pessoas, se aproximaram e mudaram minha posição, me colocando deitada no chão. Elas puseram as mãos em cima de meu abdômen e peito e aguardaram o desaparecimento dos sinais, observando minha boca e meu olhar e sorrindo afetuosamente. Posteriormente, me explicaram que eu estava me "desconectando da realidade" ao realizar o movimento de olhos fechados, o que teria a ver com traços da minha estrutura, muito mental. As sensações que tive foram referentes ao grande movimento da energia em direção à mente. Еra importante, então, manter os olhos abertos para que meu organismo não reincidisse no mecanismo de fuga da realidade provocado pelos olhos fechados. A intervenção do toque realizada em mim provocaria o estímulo da percepção no corpo pela sensação do tato, e permitiria o retorno da energia. O toque aparece como uma intervenção frequente no trabalho da bioenergética.

Certa vez, uma outra terapeuta me relatou sobre um paciente que possuía tamanha carência afetiva que durante os atendimentos era enrolado em um cobertor e acomodado no colchão com almofadas, como se fosse um recém nascido, a fim de possibilitar a experimentação do contato que lhe faltara anteriormente em sua vida.

O mesmo é narrado por Marcela quando questionada sobre suas escolhas de intervenção. Ela ressalta que o tema acessado pela sua percepção do corpo do outro seria definidor da estratégia de atuação do analista bioenergético.

As necessidades emocionais e afetivas podem ser observada nos padrões corporais da estrutura. A escolha da intervenção corporal realizada - seja uma sugestão de exercício, seja o toque terapêutico - não é acompanhada pela necessidade de uma explicação verbal pelos terapeutas aos seus clientes. Ou seja, a atuação consiste na síntese entre narrativa verbal da queixa e os elementos estruturais percebidos.

A habilidade desenvolvida para o ofício também é aplicável na manutenção da própria saúde. Aos 76 anos, Gal relatou que ao receber um diagnóstico difícil - uma 
recomendação cirúrgica - decidiu utilizar do aparato técnico aprendido em sua trajetória profissional como analista bioenergética e terapeuta ocupacional para entender seu sintoma e cuidar de seu si, conseguindo reverter o quadro ao iniciar uma rotina de exercícios de mobilização pélvica que eram gerados por um padrão energético de que gerava rigidez na região. Mas, em vez de exercícios convencionais de bioenergética, Gal escolheu o forró como ferramenta de cuidado com seu corpo.

"Estes pressupostos [dos estudos de cognição] são, especificamente, que o conhecimento é informação, e que seres humanos são mecanismos para processá-lo. Devo argumentar que, pelo contrário, nosso conhecimento consiste, em primeiro lugar, em habilidades, e que todo ser humano é um centro de percepções e agência em um campo de prática" (INGOLD, 2010, p. 7).

Com base na noção de skill, podemos perceber as técnicas utilizadas nos atendimentos como resultantes de uma construção de destreza, cuidado e julgamento que possibilita a ação através da percepção e interação com o ambiente ao seu redor, elaborando um saber-fazer pautado na constante relação consigo e o outro - cliente(s) - a durante os atendimentos. Como disse Marcela certa vez: todo terapeuta tem uma intuição muito aguçada e sensibilidade grande a nivel de sentidos. Ao enfatizar tais qualidades em detrimento de outros aspectos relacionados à racionalidade, Marcela ressalta a importância dos afetos para a construção do ofício de terapeuta.

Acredito que a noção de skill pode ser relacionada às vertentes psicanalíticas e póspsicanalíticas de modo geral, ao menos nas ramificações em que a prática psicoterápica pessoal é condição sine qua non para a constituição e aprendizagem do ofício. Ao privilegiar o entendimento da corporalidade como dimensão da subjetividade, o caso das terapias corporais pode ser colocado em diálogo com a crítica acerca da racionalidade científica ocidental e das práticas de saúde dela derivadas, seja por seus fundamentos teóricos, seja pelas transformações na sociedade que possibilitam a difusão do campo no Brasil e no mundo.

\section{CONCLUSÃO}

O debate acerca das psicoterapias corporais é complexo e demanda esforços compreensivos para além dos meandros da Nova Era. Ao passo que as análises sobre o fenômeno do ponto de vista do tensionamento das dicotomias natureza-cultura e suas derivações (corpo-mente, indivíduo-sociedade, objetivo-subjetivo, dentre outras) fornecem ferramentas teóricas para discussão, ressalta-se a importância dos estudos sobre a "cultura psicológica" para compreensão mais ampla do tema. De certo modo, as noções produzidas pela cultura "psi" também demonstram estabelecer relação com essa "cultura mais ampla da subjetividade no contemporâneo", como bem sinalizou Maluf (2005). 
No ponto de vista das habilidades necessárias ao exercício da profissão, os terapeutas seguem o legado psicanalítico e a importância dada por ele na dimensão da experiência para a construção do aprendizado. Nesse sentido, ao se submeterem ao processo terapêutico, descobrem que podem elaborar uma nova subjetividade para si e outros: a de pessoas integradas.

Assim sendo, a disjunção corpo-mente é fundamental para se entender a atuação da terapêutica, uma vez que sua compreensão de saúde é também pautada pela horizontalização destes domínios e pela apreensão do corpo para além da biologia, fornecendo insumos para contribuição do debate acerca do tema nas ciências sociais.

\section{REFERÊNCIAS}

ALBUQUERQUE, L. As invenções do corpo: modernidade e contramodernidade. MOTRIZ - Revista de Educação Física - UNESP, vol. 7, n.1, p. 33-9, 2001.

ANTONIO, Maria Carolina de Araújo. A ética do desejo: estudo etnográfico da formação de psicanalistas em escolas lacanianas de psicanálise. Tese de doutorado. São Carlos: UFSCar, 2015.

BRASIL. Ministério da Saúde. Secretaria de atenção à Saúde. Departamento de Atenção Básica Conhecendo as Práticas Integrativas e Complementares em Saúde: Bioenergética. [recurso eletrônico] / Ministério da Saúde, Secretaria de Atenção à Saúde, Departamento de Atenção Básica, Coordenação Nacional de Práticas Integrativas e Complementares em Saúde. - 1. ed. - Brasília: Ministério da Saúde, 2018.

BERLINCK, M. T. "Difusão e construção". In: Joel Birman. (Org.). Freud 50 anos depois. Rio de Janeiro: Relume-Dumará, 1989.

BERLINCK, M.T. "Transmissão e Laço Social da Psicanálise no Brasil". In: ROPA, D. (Org.). Anuário Brasileiro de Psicanálise. Rio de Janeiro: Relume-Dumará, 1991.

CAROZZI, M. J.. “Nova Era: a autonomia como religião". In: CAROZZI, Maria Julia (org.). A Nova Era no Mercosul. Petrópolis: Vozes, 1999. p. 149-187.

CASTEL, Robert. A gestão dos riscos. Rio de Janeiro: Francisco Alves, 1987.

CASTRO, Eduardo Viveiros de. Os pronomes cosmológicos e o perspectivismo ameríndio. Mana, v. 2, n. 2, p. 115-144, 1996.

CSORDAS, Thomas. Embodiment and experience: the existential ground of culture and self. Cambridge: Cambridge University Press, 1994.

D'ANDREA, A. 0 Self Perfeito e a Nova Era: Individualismo e Reflexividade em Religiosidades PósTradicionais. São Paulo: Ed. Loyola, 2000.

FOUCAULT, Michel. 0 nascimento da clínica. Rio de Janeiro: Forense Universitária, 1977. 
GUIMARÃES, F. Traços da contracultura na cultura brasileira da década de 1960: um estudo comparado entre movimentos contraculturais nos Estados Unidos e no Brasil. Anais do Encontro Regional ANPH, 2012.

INGOLD, Tim. The perception of the environment: essays on livelihood, dwelling and skill. Londres e Nova Yorque: Routledge, 2000.

Andando na prancha: meditações sobre um processo de habilidade. In: INGOLD, Tim. Estar vivo: ensaios sobre movimento, conhecimento e descrição. Petrópolis, RJ: Vozes, 2015. p. 95-110.

Trazendo as coisas de volta à vida: emaranhados criativos num mundo de materiais. Horizontes Antropológicos, v. 18, n.37, p. 25-44, 2012. 6-25, 2010.

Da transmissão de representações à educação da atenção. Educação, Porto Alegre, v. 33, n. 1, p.

Being alive: essays on movement, knowledge and description. New York: Routledge, 2011.

Making: Anthropology, Archaeology, Art and Architecture. Londres/Nova York: Routledge, 2013.

. Five questions of skill. Cultural Geographies, n. 25, p. 159-163, 2018.

. Como falar do corpo? A dimensão normativa dos estudos sobre a ciência. In: LATOUR, Bruno. Objectos Impuros: Experiências em Estudos sobre a Ciência. Porto: Afrontamento, 2008. p. 39-61.

LE BRETON, D. Antropologia Do Corpo E Modernidade. Petrópolis: Editora Vozes; 2011.

LEENHARDT, M. Do Kamo. La personne et le mythe dans le monde mélanésien. Paris, Gallimard, 1947.

LOCK, Margaret. Cultivating the body: Anthropology and epistemologies of bodily practice and knowledge. Annual Review of Anthropology, v. 22, n. 1, p. 133-155, 1993.

LOWEN, Alexander. 0 corpo em terapia: a abordagem bioenergética [1977]. São Paulo: Summus, 1988. . Exercícios de Bioenergética: o caminho para uma saúde vibrante. São Paulo: Ágora, 1985.

MALUF, Sônia. Criação de si e reinvenção do mundo: Pessoa e cosmologia nas novas culturas espirituais no sul do Brasil. Antropologia em Primeira Mão, v. 81, p. 4-34, 2002.

. Da mente ao corpo? A centralidade do corpo nas culturas da Nova Era. Ilha. Revista de Antropologia (Florianópolis), v. 7, n. 1, p. 147-161, 2005.

. Por uma antropologia do sujeito: da Pessoa aos modos de subjetivação. Campos, v. 14, n. 1-2, p.131-158, 2013.

MAUSS, M. As técnicas do corpo [1934]. In: Sociologia e antropologia. São Paulo: Cosac \&amp; Naify, 2003. 
MENDONÇA, R. L. A castração e o tempo. Instituto de Psicanálise e Saúde Mental de Minas Gerais Almanaque On-line, n. 7, p. 1-7, 2012.

NASCIMENTO, P. D. Análise Bioenergética do Sofrimento Orgânico: Diagnóstico e Eficácia do Tratamento. Tese (Doutorado). Programa de Estudos Pós- Graduados em Psicologia Clínica - PUCSP 2012.

OLIVEIRA, A. Corpos e Corporeidade no Universo da Nova Era no Brasil. Cuerpos, emociones y sociedad, v. 7, n. 3, p. 52-64, 2012.

RUSSO, J. A. 0 corpo contra a palavra: as terapias corporais no campo psicológico dos anos 80 . Tese de doutorado, Rio de Janeiro, PPGAS-Museu Nacional/UFRJ, 1993.

RUSSO, J. A. 0 mundo psi no Brasil. Rio de Janeiro: Zahar, 2002.

RUSSO, J. Tornar-se terapeuta corporal: a trajetória social como processo de "autoconstrução". Physis [online], v.1, n.2, p.113-125, 1991.

SAHLINS, M. The teach-ins: Anti-war protest in the Old Stoned Age. Anthropology Today, v. 25, n. 1, p. 3-5, 2009.

SANTOS, G. C. Terapeutas corporais: subjetividade, aprendizagem e integração na bioenergética. 2018. 144 f., il. Dissertação (Mestrado em Antropologia Social) - Universidade de Brasília, Brasília, 2018.

SEEGER, A.; DA MATTA, R.; VIVEIROS DE CASTRO, E. A construção da pessoa nas sociedades indígenas brasileiras. Boletim do Museu Nacional, n. 32, p. 2-19, 1979.

SIMONDON, G. L'Individuation psychique et collective [1969], Paris: Aubier, 2001.

SIMONDON, G. "The genesis of the individual". In: CRARY, Jonathan; KWINTER, Sanford. Incorporations -Zone 6. New York: Zone Books, 1992. p.297-319

TAVARES, F. et al. Movimento Nova Era e a reconfiguração do Social (da contracultura à heterodoxia terapêutica). AntropolíticA, n. 28, p. 177-196, 2010.

TAVARES, F. Alquimista da Cura: a rede terapêutica alternativa em contextos urbanos. Salvador: Edufba, 2012.

TONIOL, R. Do espírito na saúde. Oferta e uso de terapias alternativas/complementares nos serviços de saúde pública no Brasil. Universidade Federal do Rio Grande do Sul. Tese de doutorado. 2015.

The offer of alternative/complementary therapies in the Brazilian public health system and considerations about the limits of the New Age. In: SAIZAR, Mercedes; BORDES, Mariana (0rg.). Alternative therapies in Latin America: policies, practices and beliefs. 1ed.New York: Nova Science, 2017. p. 02-37. 